\title{
ОБЗОР ФОТОПОЛИМЕРНЫХ СМОЛ ПРИМЕНЯЕМЫХ В СТОМАТОЛОГИИ
}

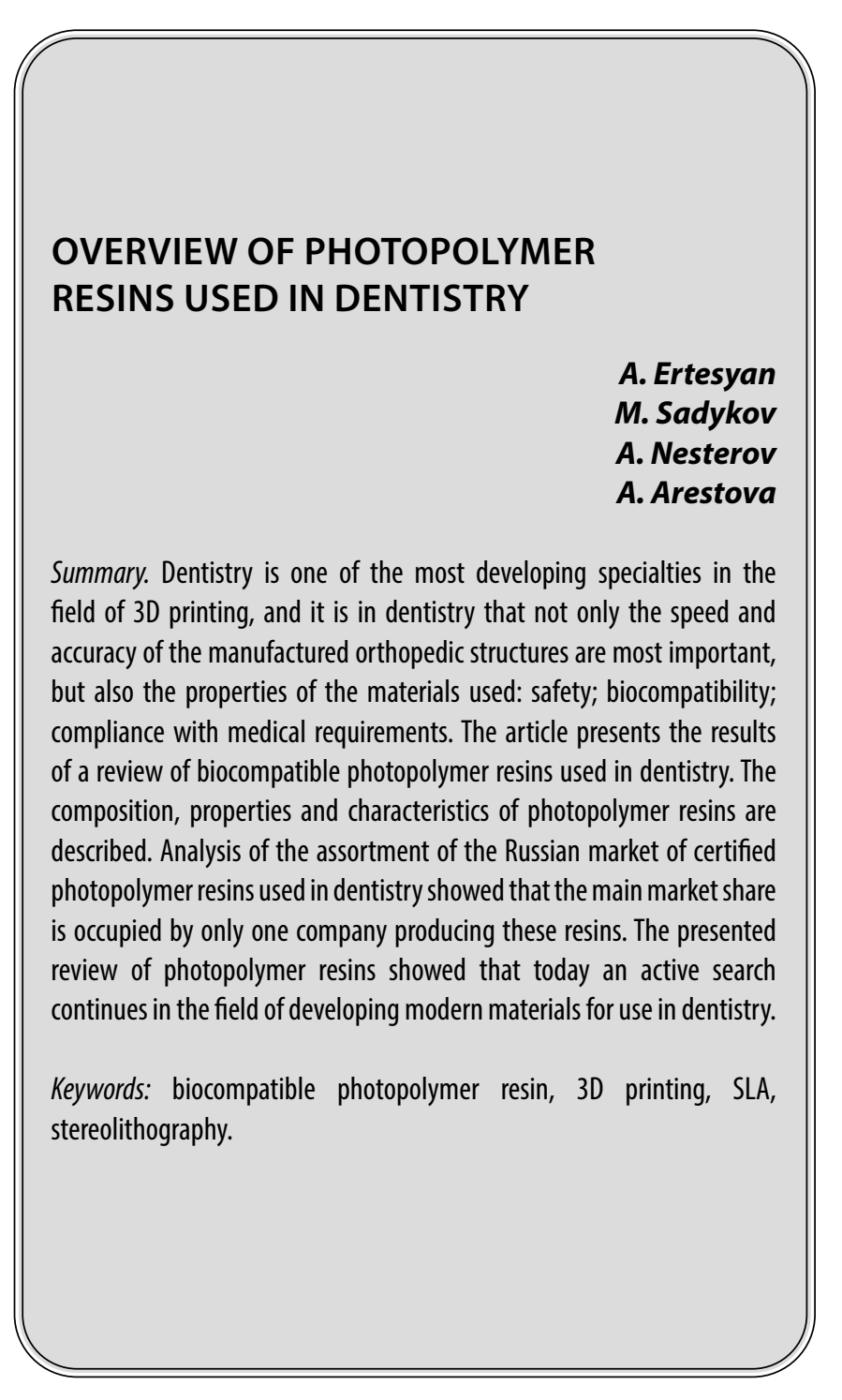

$\mathbf{M}$ атериалы, применяемые в стоматологии, весьма разнообразны. Большинство ортопедических конструкций на сегодняшний день изготавливаются из пластмасс методом 3D печати [4]. Врачи, основываясь на большом клиническом опыте, выбирают те материалы, которые обеспечивают наиболее качественную стоматологическую помощь и безопасность для пациента. Непрерывное развитие технологий в стоматологии заставляет вновь и вновь анализировать, и совершенствовать материалы, которые мы используем ежедневно в своей практике, поскольку многочисленные научные исследования свидетельствуют о том, что большинство полимеров не удовлетворяют многим
Эртесян Альберт Робертович

К.м.н., ассистент, ФГБОУ ВО «Самарский государственный медицинский университет» Минздрава России, Самара albertertesyan@gmail.com

Садыков Мукатдес Ибрагимович Д.м.н., професссор, ФГБОУВО «Самарский государственный медицинский университет» Минздрава России, Самара

Нестеров Александр Михайлович

Д.м.н., профессор, ФГБОУ ВО «Самарский государственный медицинский университет» Минздрава России, Самара

Арестова Анастасия Андреевна ФГБОУ ВО «Самарский государственный медицинский университет» Минздрава России, Самара

Аннотация. Стоматология - является одной из наиболее развивающейся специальностью в области 3D-печати, и именно в стоматологии наиболее важны не только скорость и точность изготовленных ортопедических конструкций, но и свойства используемых материалов: безопасность; биосовместимость; соответствие медицинским требованиям. В статье представлены результаты обзора биосовместимых фотополимерных смол, применяемых в стоматологии. Описан состав, свойства и характеристики фотополимерных смол. Анализ ассортимента российского рынка сертифицированных фотополимерных смол, используемых в стоматологии, показал, что основную долю рынка занимают лишь одна компания, производящая данные смолы. Представленный обзор фотополимерных смол, показал, что на сегодняшний день продолжается активный поиск в области разработки современных материалов для использования в стоматологии.

Ключевые слова: биосовместимая фотополимерная смола, 3D-печать, SLA, стереолитография.

требованиям врачей [1]. Так, на смену классическим полимерам, приходят фотополимерные смолы для 3D печати $[2,3]$.

Фотополимерные смолы HARZ Labs, компании «ХАРЦ Лабс», Россия, характеризуются высокой детализированностью и точностью готовых изделий. Кроме того, материалам свойственен минимальный процент усадки, биосовместимость, гипоаллергенность, гибкость, стабильность состава, точность, рентгенокотрастность, химическая стойкость, а также отсутствие запаха. Фотополимерные смолы линейки Dental предназначены для 3D печати по технологиям SLA, DLP, LCD. Все материалы 
Таблица 1. Технические характеристика фотополимерных смол

\begin{tabular}{|l|l|l|l|l|l|l|}
\multirow{2}{*}{ Вид исследования } & \multicolumn{2}{l}{ Фотополимерные смолы линейки Dental } & \multicolumn{4}{l|}{} \\
\cline { 2 - 8 } & Yellow Clear & Clear & Peach & Pink & Pink Soft & Sand \\
\hline $\begin{array}{l}\text { Прочность на разрыв, } \\
\text { Н/мм }\end{array}$ & $37.9-47.7$ & $35-45$ & $40.8-49.6$ & $63.0-67.2$ & $1.1-1.2$ & $51-61$ \\
\hline Удлинение на разрыв,\% & $4.7-9.7$ & $3.1-9.3$ & $4.0-10.2$ & $4.7-8.9$ & $66-70$ & $4.0-10.2$ \\
\hline Твердость по Шору, D & $72-76$ & $72-78$ & $77-81$ & $79-85$ & $52-58$ & $79-85$ \\
\hline $\begin{array}{l}\text { Вязкость } \\
\text { по Брукфильду, Па.с }\end{array}$ & 0.4 & 0.4 & 0.7 & 1.5 & 0.6 & 1.2 \\
\hline Усадка,\% & $<0.5$ & $<0.5$ & $<0.5$ & $<0.5$ & $<0.5$ & $<0.5$ \\
\hline
\end{tabular}

сертифицированы на территории РФ (РУ на медицинское изделие № Р3Н 2020/12007) и соответствуют требованиям ГОСТ Р ИСО 10993 [5].

Dental Yellow Clear - твердая РММА-подобная смола, предназначенная для 3D печати хирургических шаблонов. Материал без запаха, в своем составе не имеет вредных остаточных мономеров. Её прозрачный желтый цвет, близкий к натуральному позволяет добиться оптимальной визуализации рабочей области. Готовые хирургические шаблоны обладают высокой степенью жесткости, что обеспечивает надежную фиксацию шаблона в полости рта пациента.

Dental Clear - предназначен для печати прозрачных моделей, таких как элайнеры и каппы. Точный, прозрачный, очень жесткий и твердый и без запаха. Фотополимep Dental Clear представляет собой РММА-подобную прозрачную смолу, предназначенную для печати моделей, используемых в стоматологии, где прозрачность является одной из основных проблем.

Dental Peach - представляет собой матовую смолу бледно-оранжевого цвета, изготовленную из биосовместимого сырья, которое используется в зубных пломбах с УФ-отверждением. Смола предназначена для термоформовки различных корректирующих устройств, в частности элайнеров. Для изделий из этой смолы характерна кратковременная стабильность при температуре более $180^{\circ}$ и долгосрочная стабильность при температуре $100^{\circ}$. Благодаря этому материал может использоваться для изготовления демонстрационных и мастер-моделей.

Dental Pink - полупрозрачный фотополимер розового цвета, который максимально приближен к естественным тканям. Материал предназначен для имитации десны и десневых тканей. Полимер может использоваться и для других задач, в частности, для печати моделей ушного канала в челюстно-лицевой ортопедии. При изготовлении этого полимера используется биосовмести- мое сырьё, что делает его безопасным для применения в стоматологии.

Dental Soft Pink - необходим для замены силиконового материала, который используется в стоматологии для точного воспроизведения десневой маски. Обеспечивает идеальную посадку и естественную эстетику ортопедической конструкции. Механические свойства близки к естественной десне: гибкость и мягкость, необходимые для имитации поведения десны пациента при точной посадке имплантатов.

Dental Sand A1, A2, A3 и Bleach - полимерные смолы с микрокерамическим наполнением, предназначенные для 3D печати временных коронок и мостовидных протезов. Конструкции отличаются высокой стойкостью к агрессивным средам (щелочь, кислота, биологические среды) и механической прочностью. По своим свойствам смола напоминает РММА-материал. Материал после дозасветки имеет цвет A1, A2, A3 или Bleach по шкале Vita.

Dental Cast - смола, предназначенная для печати моделей под прямое литье, обладающая высокой детализацией и нулевой зольностью. Материал в кратчайшие сроки выгорает при высоких температурах, не оставляя золы. Благодаря этому появляется возможность изготовления высокоточных металлических и керамических мостов, коронок, имплантатов, каркасов бюгельных протезов.

В таблице 1 представлены технические характеристики фотополимерных смол линейки Dental Harz Labs.

Таким образом, стоматологические фотополимерные смолы компании «HARZ Labs» могут быть использованы в зуботехнической лаборатории и стоматологии. Материалы обладают стабильностью результатов печати, высокой точностью и качеством протеза, биосовместимостью и твердостью. Все смолы имеют регистрационное удостоверение на медицинское изделие и соответствуют требованиям ГОСТ. 


\section{ЛИТЕРАТУРА}

1. Штана В.С., Рыжова И.П. Обзор современных базисных полимеров в ортопедической стоматологии / В.С. Штана, И. П. Рыжова // Научные ведомости Белгородского государственного университета. Серия: Медицина. Фармация. 2019.— № . 42 (2). — C. 224-234. D0I: 10.18413/2075-4728-2019-42-2224-234

2. ХАРЦ Лабс. URL: https://www.harzlabs.com/products/ (19.10.2020)

3. Малаев И.А., Пивовар М. Л. Аддитивные технологии: применение в медицине и фармации / И. А. Малаев, М. Л. Пивовар // Вестник фармации.-2019.№. 2. - С. 98-107.

4. Эртесян А.Р., Садыков М. И., Нестеров А. М. Обзор технологий 3D- печати в стоматологии / А. Р. Эртесян, М. И. Садыков, А. М. Нестеров // Медико-фармацевтический журнал «ПУЛЬС®. — 2020 — Том. 22. — № 10. — С. 15-18. http://dx.doi.org/10.26787/nydha-2686-6838-2019-22-10

5. ГОСТ Р ИСО 10993. Изделия медицинские.; введ. 01.09.2010.—АНО «ИМБИИТ»: М.: Стандартинформ, 2009.— 16 с.

( ) Эртесян Альберт Робертович ( albertertesyan@gmail.com ), Садыков Мукатдес Ибрагимович,

Нестеров Александр Михайлович, Арестова Анастасия Андреевна.

Журнал «Современная наука: актуальные проблемы теории и практики»

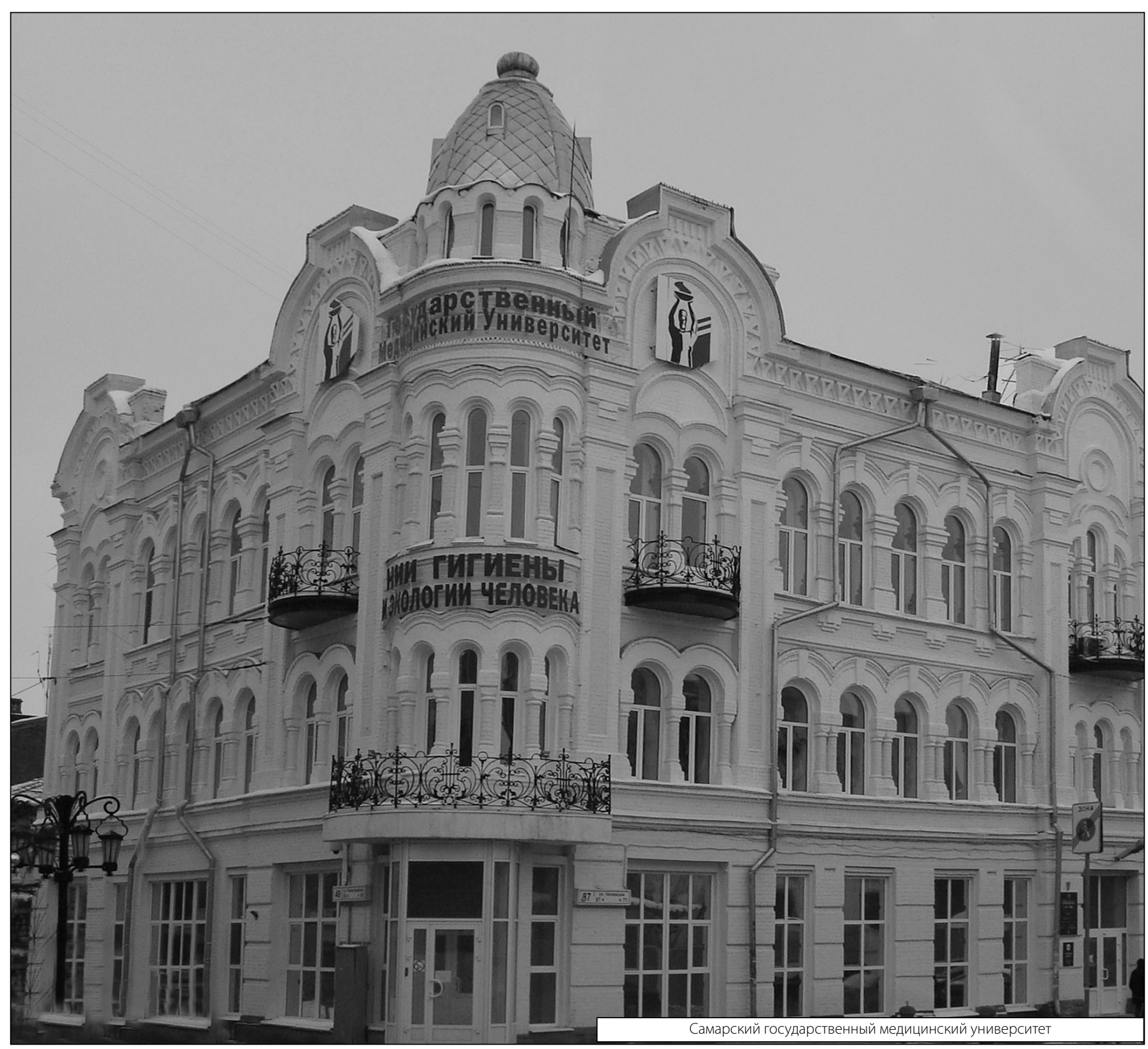

